\title{
Regional analysis of parameter sensitivity for simulation of streamflow and hydrological fingerprints
}

\author{
Simon Höllering ${ }^{1}$, Jan Wienhöfer ${ }^{1}$, Jürgen Ihringer ${ }^{1}$, Luis Samaniego ${ }^{2}$, and Erwin Zehe ${ }^{1}$ \\ ${ }^{1}$ Karlsruhe Institute of Technology (KIT), Karlsruhe, Germany \\ ${ }^{2}$ Helmholtz Centre for Environmental Research, Leipzig, Germany \\ Correspondence: Simon Höllering (simon.hoellering@kit.edu)
}

Received: 20 July 2017 - Discussion started: 21 July 2017

Revised: 13 October 2017 - Accepted: 19 November 2017 - Published: 11 January 2018

\begin{abstract}
Diagnostics of hydrological models are pivotal for a better understanding of catchment functioning, and the analysis of dominating model parameters plays a key role for region-specific calibration or parameter transfer. A major challenge in the analysis of parameter sensitivity is the assessment of both temporal and spatial differences of parameter influences on simulated streamflow response. We present a methodological approach for global sensitivity analysis of hydrological models. The multilevel approach is geared towards complementary forms of streamflow response targets, and combines sensitivity analysis directed to hydrological fingerprints, i.e. temporally independent and temporally aggregated characteristics of streamflow (INDPAS), with the conventional analysis of the temporal dynamics of parameter sensitivity (TEDPAS).

The approach was tested in 14 mesoscale headwater catchments of the Ruhr River in western Germany using simulations with the spatially distributed hydrological model mHM. The multilevel analysis with diverse response characteristics allowed us to pinpoint parameter sensitivity patterns much more clearly as compared to using TEDPAS alone. It was not only possible to identify two dominating parameters, for soil moisture dynamics and evapotranspiration, but we could also disentangle the role of these and other parameters with reference to different streamflow characteristics. The combination of TEDPAS and INDPAS further allowed us to detect regional differences in parameter sensitivity and in simulated hydrological functioning, despite the rather small differences in the hydroclimatic and topographic setting of the Ruhr headwaters.
\end{abstract}

\section{Introduction}

\subsection{Analysis of parameter influences}

The role of hydrological model parameters has been studied for a long time. The ill-posed nature of problems in hydrological modelling led to the awareness that parameter sets are not uniquely identifiable (Beven, 1993) and to the related branches of uncertainty assessment (e.g. Gupta et al., 1998) and automated parameter estimation (e.g. Hogue et al., 2000). Both are closely related to the sensitivity of model results to parameter variations. While a number of topics are often subsumed under sensitivity analysis, underlying objectives and methodological approaches can substantially differ from case to case (van Griensven et al., 2006; Saltelli et al., 2008; Zajac, 2010; Razavi and Gupta, 2015). Local and global strategies of sensitivity analysis have been shown to be helpful at different stages of the modelling process (McCuen, 1973; Hamby, 1994; Sieber and Uhlenbrook, 2005; Razavi and Gupta, 2015). Analogous to the number of different objectives and methods to assess parameter sensitivity, the results are subject to different forms of interpretation (Razavi and Gupta, 2015). The way that the outcome of sensitivity analysis is evaluated and illustrated can strongly affect the conclusions that are drawn. In this regard, results of sensitivity analysis can widely differ if varying objective functions are considered for the evaluation of parameter influences (Demaria et al., 2007; Wagener et al., 2009); for a comprehensive overview see Reusser et al. (2011).

Time-integrated sensitivity measures (van Griensven et al., 2006; Sudheer et al., 2011; Nossent and Bauwens, 2012) alone allow little more than rough estimates about the overall importance of parameters. Contrarily, McCuen (1973) early 
pointed out that parameter sensitivity should be analysed in a time-dependent context, as hydrological systems are subject to temporally dynamic processes. Guse et al. (2016b) argued that the study of temporal variations in sensitivity is essential to learn about the relation between dominant parameters and governing processes under changing hydrological conditions. The characterisation of temporal dynamics of parameter sensitivity (TEDPAS) has been accomplished in diverse ways (Cloke et al., 2008; Cibin et al., 2010; Reusser et al., 2011; Reusser and Zehe, 2011; Herman et al., 2013; Sanadhya et al., 2013; Guse et al., 2014; Pfannerstill et al., 2015; Pianosi and Wagener, 2016). The choice of the temporal resolution is an important factor which clearly influences the way parameters are identified and how inferences on related processes are made (Tang et al., 2007; Massmann and Holzmann, 2012; O'Loughlin et al., 2013). Necessarily, the timescale of sensitivity analysis is selected in accordance with the objective of the study and the dynamics of the system under investigation. The importance of parameters temporally varies as short periods of high flow alternate with longer periods of low flow (Massmann et al., 2014).

When model calibration and verification come into play, analysis of parameter sensitivity provides valuable information on the importance of each input factor in regard to simulated model output. On this basis, it can be decided for each parameter whether its value should be determined exactly, or if it could even be completely excluded, fixed at predetermined values (Reusser et al., 2011). Preferably, sensitivity analysis minimises the necessary number of parameters as hydrological models are often subject to overparameterisation (Beven, 2001; Kirchner, 2006; van Werkhoven et al., 2009; Samaniego et al., 2010b).

A common goal of sensitivity-guided studies dealing with an identification of dominant processes is the achievement of a suitable representation of real-world hydrological processes by understanding the reasons for model defectiveness. If non-sensitive parameters are detected, an indication of model structural deficits (Kirchner, 2006; Gupta et al., 2012), or a lack of the adequate model response target data might be given. Sensitivity analysis is, not just recently, considered as a helpful diagnostic tool to identify structural and performance deficits of hydrological models (McCuen, 1973; Sieber and Uhlenbrook, 2005; Yilmaz et al., 2008; Kavetski and Clark, 2010; Guse et al., 2014; Pfannerstill et al., 2015). Reusser and Zehe (2011) showed that a combined analysis of the temporally varying parameter dominance (sensitivity analysis) and model performance (error analysis) can effectively detect structural inadequacies of model components for a specific landscape.

\subsection{Fingerprint-based sensitivity analysis}

The characterisation of catchment functioning and the underlying hydrological processes can be addressed in various ways, at multiple scales and levels of complexity. Fingerprint metrics (hereinafter also referred to as fingerprints) are signatures of dynamic catchment response that change on different temporal and spatial scales (Sivapalan, 2005; Wagener et al., 2007; Winsemius et al., 2009).

In hydrological modelling, multiple fingerprint metrics have been adopted to enhance model evaluation beyond the minimisation of streamflow residuals. Fingerprints of catchment functioning may be classified into measures based on single-value (statistical) streamflow indices, and those based on characteristic curves, e.g. (cumulative) frequency curves, regime curves, or double mass curves. Examples for the two kinds of fingerprint metrics are the runoff ratio and the flow duration curve, respectively. Representatives of both categories can be selected to describe single components of streamflow regimes, namely the magnitude, frequency of occurrence, duration, timing, and flashiness of flow events (Poff et al., 1997; Olden and Poff, 2003), or of the general hydrological variability at different spatial and temporal scales.

In a comprehensive analysis of catchment functioning in order to understand dominant processes, the use of a single criterion is often not sufficient. Therefore, hydrological fingerprints have been jointly used as multivariate objectives to estimate the parameters of hydrological models (Shamir et al., 2005a, b; Pokhrel et al., 2008; Castiglioni et al., 2010) or to assess model performance and evaluate model structures (Farmer et al., 2003; Gupta et al., 2008; Yilmaz et al., 2008; Clark et al., 2011; Euser et al., 2013; Vrugt and Sadegh, 2013).

Sensitivity analysis related to streamflow characteristics was formerly mostly applied prior to model evaluation (e.g. Atkinson et al., 2003). For sensitivity analysis, different options have been selected as hydrological target variables. Sensitivity analysis to assess the influence of parameters can be directed to (i) simulated streamflow, (ii) different objective functions (e.g. van Werkhoven et al., 2009; Wagener et al., 2009; Herman et al., 2013; Sanadhya et al., 2013), (iii) simulated hydrological processes (e.g. Massmann and Holzmann, 2015; Pfannerstill et al., 2015; Guse et al., 2016a), or (iv) different hydrological fingerprints (this study). Previous studies applied fingerprint metrics but based the analysis of parameter sensitivity on only a few aspects of streamflow (e.g. limb densities; Shamir et al., 2005a) or on single (statistical) streamflow indices of different aggregation timescales (Shamir et al., 2005b).

In our view, multivariate sensitivity analysis geared towards fingerprint metrics as response targets has not received adequate consideration for model diagnostics. Especially in terms of joint fingerprints, using both single-value indices and characteristic curves along independent variables, the full potential for process-oriented model diagnostics has not been exploited. Some progress has been made by Guse et al. (2016b), who combined TEDPAS for different temporal resolutions with segments of the flow duration curve (FDC) to identify parameters and related processes that dominate at 
variable streamflow magnitudes of two distinct streamflow regimes.

\subsection{Objectives, research questions and approach}

The main objectives of this study are to analyse the parameter sensitivity of a mesoscale hydrological model for the simulation of streamflow response and hydrological fingerprints at a set of headwater catchments of the Ruhr in Germany. The approach extends TEDPAS along two avenues: the first is to investigate TEDPAS results in more detail to derive parameter sensitivities in different hydrological conditions; the second is to direct the analysis to other, temporally independent characteristics of streamflow response (INDPAS).

With this approach we explore the following three research questions:

- Which sensitive parameters can be identified with regard to specific hydrological response characteristics?

- How does parameter sensitivity change with different hydrological objectives (response targets) applied in global sensitivity analysis?

- How does parameter sensitivity change among different catchments with slightly distinct physiographic and hydroclimatic conditions?

The methodological approach combines streamflow hydrographs and fingerprint metrics as response targets for the analysis of first-order partial parameter sensitivity. The analysis rests on a state-of-the-art distributed hydrological model and is structured in the following steps:

- combining the application of a hydrological model with global sensitivity analysis to generate an ensemble of parameter sets;

- deriving fingerprint metrics (single-value indices and characteristic curves) from simulated streamflow time series;

- analysing parameter sensitivity to temporally resolved dynamics of streamflow response (TEDPAS);

- analysing parameter sensitivity to both temporally aggregated (single-value indices) and temporally independent (characteristic curves) characteristics of streamflow (INDPAS);

- assessing differences in parameter sensitivity between the two different methodological approaches (TEDPAS and INDPAS), and between the analysed headwaters.

In the study we will thus complement sensitivity analysis based on TEDPAS with fingerprint metrics of streamflow response (INDPAS), which include both temporally aggregated single-valued indices and temporally independent characteristic curves. In cases where characteristic curves (e.g. the FDC) are used, changes in parameter sensitivity will be analysed for changes in the independent variable (e.g. streamflow exceedance probability). We focus the study on the headwaters of the Ruhr catchment in western Germany based on available data sets.

From this we expect to pinpoint dominant parameters related to individual process components and to ease the interpretation of parameter sensitivity detached from the variability of timescales. Bearing in mind the complexity of the evaluation of spatially and temporally distributed model responses, our multilevel approach aims at providing further insight into the dominance of model parameters and related streamflow response processes.

\section{Methods and models}

First we detail the fingerprint metrics used to characterise streamflow response (Sect. 2.1). We implemented the Fourier amplitude sensitivity test (FAST; Sect. 2.2) to analyse the mesoscale hydrologic model (mHM, Sect. 2.3) in the Ruhr headwater catchments. Focusing on eight global mHM parameters (Sect. 2.4), we employed two different forms (TEDPAS and INDPAS) of simulated streamflow response (Sect. 2.5) in the sensitivity analysis. Finally, we introduce the catchment of the Ruhr River and the headwaters which were selected for this study (Sect. 2.6.1), and specify the data used for the analysis (Sect. 2.6.2).

\subsection{Fingerprint metrics}

Fingerprint metrics are often used in hydrology for characterising the hydrological response of catchments (Olden and Poff, 2003; Yadav et al., 2007; Yilmaz et al., 2008; Winsemius et al., 2009). The fingerprint metrics used in this study included single-value indices and the flow duration curve as an example for catchment-characteristic curves. These fingerprints were derived from model results and precipitation data (see Sect. 2.6.2), respectively.

We chose eight indices reflecting different aspects of the integral and long-term hydrological functioning of catchments in a single, time-aggregated number (Table 1). These fingerprints characterise the overall water balance (runoff ratio, RR), the variability of streamflow (coefficient of variation, CV), the frequency of flow events (high pulse count, HPC), the change rate of streamflow (slope of flow duration curve between 33 and $66 \%$, SLFDC), the streamflow during high-flow (high flow discharge, HFD) and low-flow (baseflow index, BFI) conditions, the streamflow recession behaviour (recession time constant, RTC), and the autocorrelation structure of streamflow (autocorrelation time, ACT), respectively. In this study, the slope of the flow duration curve (SLFDC) is the only single-value fingerprint that could 
Table 1. Temporally aggregated single-value fingerprint metrics derived from FAST-mHM simulated streamflow and observed precipitation time series, serving as model response targets for sensitivity analysis (INDPAS).

\begin{tabular}{|c|c|c|c|c|}
\hline Response characteristic & Fingerprint metric & Abbreviation & Unit & Derivation \\
\hline Water balance & Runoff ratio & $\mathrm{RR}$ & $(-)$ & $Q_{\text {Total }} / P_{\text {Total }}$ \\
\hline Streamflow variability & Coefficient of variation & $\mathrm{CV}$ & $(-)$ & $\sigma / \mu$ \\
\hline Frequency of flow events & High pulse count & HPC & $\left(\mathrm{yr}^{-1}\right)$ & $\begin{array}{l}\text { (number of time steps } \\
\left.Q>3 \times Q_{\text {mean }}\right) / \text { years }\end{array}$ \\
\hline Rate of change in streamflow & $\begin{array}{l}\text { Slope of flow duration } \\
\text { curve }\end{array}$ & SLFDC & $(\%)$ & $\begin{array}{l}\text { Slope of FDC between } 33 \text { and } 66 \% \\
Q \text { exceedance }\end{array}$ \\
\hline High-flow conditions & High flow discharge & HFD & $(-)$ & $Q_{5 \text { th }}$ percentile $/ Q_{\text {median }}$ \\
\hline Low-flow conditions & Baseflow index & BFI & $(-)$ & $Q_{\text {Baseflow }} / Q_{\text {Total }}$ \\
\hline Streamflow recession & Recession time constant & RTC & (d) & $\begin{array}{l}\text { Mdn (time required for } Q \text { to } \\
\left.\text { reach } 1 / e \times Q_{\text {Peak }}\right)\end{array}$ \\
\hline $\begin{array}{l}\text { Streamflow autocorrelation } \\
\text { structure }\end{array}$ & Autocorrelation time & ACT & (d) & $\begin{array}{l}\text { Lag time required for } \mathrm{AC} \text { function } \\
\text { to decrease below } 0.5\end{array}$ \\
\hline
\end{tabular}

$Q$ : streamflow; $P$ : precipitation; $\sigma$ : standard deviation; $\mu$ : mean; Mdn: median; AC: autocorrelation.

not be directly determined from streamflow hydrographs. Instead, the FDC was used as a basis for its derivation. The eight single-value fingerprints were implemented as model response targets for sensitivity analysis (Sect. 2.5.2).

As an example for more complex characteristics than single-valued indices, we also used entire flow duration curves as model response targets for sensitivity analysis (Sect. 2.5.2).

\subsection{Fourier amplitude sensitivity test (FAST)}

FAST is a partial variance-based method to determine firstorder sensitivities of parameter changes on the outcome of monotonic and non-monotonic numeric models (Cukier et al., 1973; Schaibly and Shuler, 1973; Cukier et al., 1975). The general idea of FAST is (a) to vary parameters of interest with independent frequencies along a predefined number of model runs, and (b) to perform a Fourier analysis of the simulated target variable across the ensemble of model runs to obtain a power spectrum. In the case of TEDPAS, the spectrum is calculated for each simulation time step. The variance $\sigma_{i}^{2}$ that is explained by a parameter $i$ is determined by normalising the corresponding power with the total power in the spectrum, which corresponds to the total variance $\sigma_{\text {tot }}^{2}$ within the model ensemble. The sensitivity to model output of parameter $i$ is then calculated as the partial variance, which is the ratio $\sigma_{i}^{2} / \sigma_{\text {tot }}^{2}$. Parameter interactions, i.e. higher-order sensitivity, are not detected by this method. For more details on FAST the reader is referred to Reusser et al. (2011).

FAST was originally applied to study parametric model sensitivities of chemical reaction systems. In recent decades, the method has been used and evaluated in a variety of fields such as hydrogeology (Fontaine et al., 1992), atmospheric sciences (Rodríguez-Camino and Avissar, 1998), geologic nuclear waste disposal modelling (Lu and Mohanty, 2001), food safety risk assessment (Frey and Patil, 2002), or eco- logic forestry (Song et al., 2013). A number of studies treat the application of FAST in hydrological modelling (Reusser et al., 2011; Reusser and Zehe, 2011; Sanadhya et al., 2013; Guse et al., 2014; Pfannerstill et al., 2015; Guse et al., 2016a, b).

FAST is a highly efficient computational method that requires significantly fewer model runs to yield similar results for parameter sensitivity than other approaches (Saltelli and Bolado, 1998; Reusser et al., 2011). The number of model runs (hence parameter sets) in FAST is determined by the number of analysed model parameters. This means that always the same number of model runs is required for a given number of parameters, independent of model, catchment or type of parameter.

\subsection{Mesoscale hydrologic model (mHM)}

The mHM (Kumar et al., 2010; Samaniego et al., 2010b) accounts for diverse processes of the hydrological cycle: canopy interception, evapotranspiration, snow, soil moisture dynamics, overland flow, infiltration, interflow, subsurface storage, groundwater recharge, baseflow, discharge attenuation, as well as flood routing. The mHM is conceptualised on the basis of grid cells, and has been applied to a wide range of mesoscale river catchments $\left(10^{1}-10^{4} \mathrm{~km}^{2}\right.$; Kumar et al., 2010; Samaniego et al., 2010a, 2011; Cuntz et al., 2015; Rakovec et al., 2016). Gridded information is implemented in mHM at three levels: morphology (level 0), hydrology (level 1), meteorology (level 2), with $l_{0} \ll l_{1} \leq l_{2}$ denoting the relative sizes of the grid cells at the respective data level (Kumar et al., 2010).

The parameterisation of $\mathrm{mHM}$ is based on a simultaneous regionalisation technique called multiscale parameter regionalisation to account for the physiographic sub-grid and hydrological process variability (Samaniego et al., 2010b; Kumar et al., 2013). Hydrological process parameters at level 
1 are derived from physiographic characteristics at level 0 using (pedo-)transfer functions with coefficients (in the following referred to as global $\mathrm{mHM}$ parameters). Hence, $\mathrm{mHM}$ is calibrated indirectly, by altering the 52 level- 0 parameters of the transfer functions instead of the hydrological level1 parameters. This procedure not only reduces the problem of overparameterisation and the dependence on specific hydrological scales (Beven, 2001) but also reduces the amount of time that is needed for grid-wise calibration (Samaniego et al., 2010b).

\subsection{Model setup for sensitivity analysis}

To facilitate the selection of the most sensitive parameters, we first carried out a preliminary FAST analysis at the local scale for gauge Wenholthausen (WEN; Fig. 1) including all 52 global mHM parameters to reveal parameter sensitivities to streamflow simulations. For this initial analysis, 21803 model runs were conducted and the streamflow hydrographs were analysed with FAST. We found 14 parameters with a maximal sensitivity value of more than $0.01(1 \%)$. When inspecting the model equations we identified correlations between these parameters, which led to the removal of six parameters from this set.

The eight uncorrelated parameters (Table 2) were used for the regional sensitivity analysis in the 14 headwater catchments. All other mHM parameters were kept fixed on calibrated values found via global automatic optimisation using the dynamically dimensioned search algorithm (Tolson and Shoemaker, 2007) at WEN for the period 2002 to 2006. The value ranges for the parameters were selected from $\mathrm{mHM}$ literature (Samaniego et al., 2014), partly extended based on the results from the preliminary analysis. For eight parameters, the FAST method requires 243 model runs based on different parameter combinations originating from variation with independent frequencies inside the parameter ranges (Fig. 2). The same 243 combinations of mHM parameter sets were used for streamflow simulations in each of the 14 catchments. Differences between catchments in terms of hydroclimatic forcing and physiographic attributes were included in the model by the locally specific meteorological and morphological input on data levels $l_{2}$ and $l_{0}$.

The hydrological model level $l_{1}$ and the meteorological $l_{2}$ of mHM were set to a spatial resolution of $1 \mathrm{~km}$, whereas for level 0 with the physiographic catchment data (morphology), a finer resolution of $l_{0}=200 \mathrm{~m}$ was selected as an adequate spatial discretisation. Model simulations were conducted for each of the 14 headwater catchments (see Sect. 2.6.1) with a daily time step for the 10-year period of 1997 to 2006.

\subsection{Sensitivity analysis}

We analysed the parameter sensitivity in different forms to be able to evaluate the dominance of parameters and to potentially detect local differences among the headwaters related to various aspects of streamflow response in a more specific way. We used simulated streamflow hydrographs (TEDPAS; Sect. 2.5.1) and both temporally aggregated and temporally independent fingerprint metrics of simulated streamflow response (INDPAS; Sect. 2.5.2) as model response targets for the sensitivity analyses.

\subsubsection{TEDPAS - temporal dynamics and sensitivity duration}

Using simulated hydrographs with FAST provided daily time series of partial parameter sensitivities for each headwater catchment for the simulation period 1997-2006. These temporal dynamics of parameter sensitivity (TEDPAS; Reusser et al., 2011) were analysed and compared for the Ruhr headwater catchments (Sect. 3.1).

We also calculated sensitivity duration curves (SDCs) for each parameter, which we defined in analogy to other wellknown cumulative frequency curves like the FDC. Each SDC is specific for one of the eight parameters, for one catchment and for the period (1997-2006) in which sensitivity analysis is performed. SDCs were developed for each catchment by arranging the daily sensitivity values from FAST by magnitude in ascending order and by plotting them as a line against the percentage of time during which the sensitivity equalled or exceeded the specified values. Sensitivities were normalised by the highest sensitivity value found for each parameter among all headwaters. These curves reveal whether a parameter is consistently (non-)sensitive or if its importance changes during the simulation period (Sect. 3.2).

\subsubsection{INDPAS - parameter sensitivity to fingerprint metrics}

For each catchment we calculated eight single-valued fingerprint metrics (Sect. 2.1 and Table 1) from each of the 243 simulated streamflow hydrographs. Using these fingerprint metrics as target variables for FAST yielded the partial sensitivities of the model parameters with regard to each fingerprint (Sect. 3.3.1).

In a similar way, for each headwater catchment, 243 flow duration curves were derived from the simulated streamflow time series and analysed with FAST. This yielded parameter sensitivities along the axis of streamflow exceedance probability as an independent variable, revealing which parameters dominate streamflow simulations during high-, intermediateor low-flow conditions. As a supplementary step, the parameters showing the highest sensitivity for a given streamflow exceedance probability were extracted, revealing patterns of dominant parameters across the spectrum of streamflow in each headwater catchment (Sect. 3.3.2). 
Table 2. Eight global mHM parameters (dimensionless): function, value range for FAST, range and arithmetic mean of sensitivity values (TEDPAS) across 14 Ruhr headwater catchments (1997-2006).

\begin{tabular}{|c|c|c|c|c|c|}
\hline Parameter & Process & Description & $\begin{array}{r}\text { Value } \\
\text { range }(-)\end{array}$ & $\begin{array}{l}\text { Sensitivity } \\
\text { range (-) }\end{array}$ & $\begin{array}{r}\text { Sensitivity } \\
\text { mean }(-)\end{array}$ \\
\hline DegdayForest & snow & $\begin{array}{l}\text { Determination of degree daily factor } \\
\text { and maximum degree-day factor }\end{array}$ & $0-4$ & $0-0.74$ & 0.012 \\
\hline ThetaSconst & soil moisture & $\begin{array}{l}\text { Estimation of water content at } \\
\text { saturation of soil (constant part) }\end{array}$ & $0.65-0.95$ & $0-0.68$ & 0.018 \\
\hline Ksconst & soil moisture & $\begin{array}{l}\text { Estimation of saturated } \\
\text { vertical hydraulic conductivity }\end{array}$ & $-1.9-0.0$ & $0-0.77$ & 0.392 \\
\hline InfilShapeFactor & soil moisture & $\begin{array}{l}\text { Determination of numerical } \\
\text { index of rooting distribution }\end{array}$ & $1-4$ & $0-0.29$ & 0.017 \\
\hline AspectcorrPET & meteo correction & $\begin{array}{l}\text { Account for aspect dependent } \\
\text { correction of PET }\end{array}$ & $0.70-1.50$ & $0-0.78$ & 0.138 \\
\hline ExpslowInterflow & interflow & $\begin{array}{l}\text { Determination of exponent } \\
\text { for the interflow reservoir }\end{array}$ & $0.05-0.3$ & $0-0.22$ & 0.062 \\
\hline RechargeCoeff & percolation & $\begin{array}{l}\text { Determination of percolation } \\
\text { coefficient }\end{array}$ & $0-70$ & $0-0.38$ & 0.057 \\
\hline GeoParam & baseflow & $\begin{array}{l}\text { Determination of baseflow } \\
\text { recession parameter }\end{array}$ & $0-1000$ & $0-0.47$ & 0.012 \\
\hline
\end{tabular}

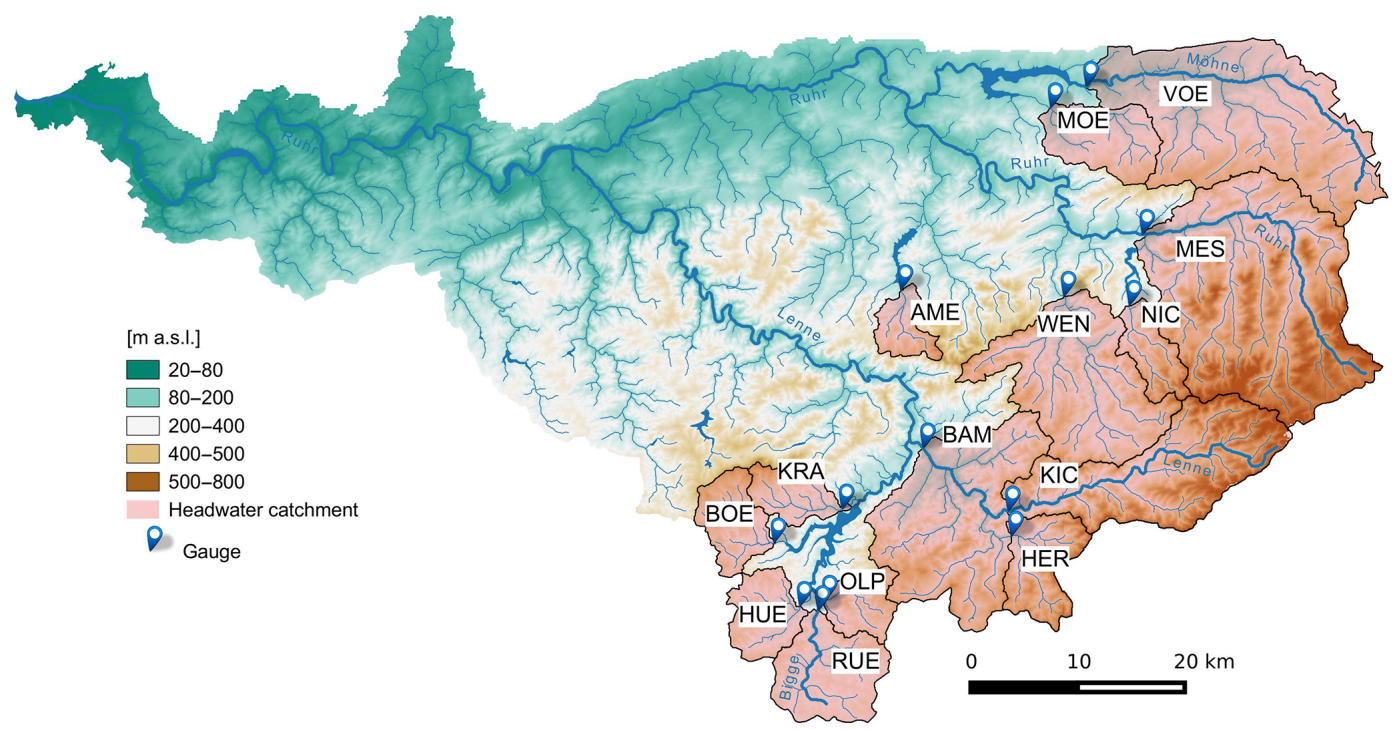

Figure 1. The Ruhr catchment with altitudinal zones, river network and 14 gauged headwater catchments: Amecke (AME), Bamenohl (BAM), Börlinghausen (BOE), Herrntrop (HER), Hüppcherhammer (HUE), Kickenbach (KIC), Kraghammer (KRA), Meschede1 (MES), Möhnesee-Neuhaus (MOE), Nichtinghausen (NIC), Olpe (OLP), Rüblinghausen (RUE), Völlinghausen (VOE), and Wenholthausen (WEN).

\subsection{Study area and data}

\subsubsection{The Ruhr headwater catchments}

The Ruhr (Fig. 1) has a catchment area of $4485 \mathrm{~km}^{2}$, and originates from a spring at about $670 \mathrm{~m}$ a.s.l. on the northern slope of the Ruhrkopf ( 842 ma.s.l.). The Ruhr joins the Rhine at Duisburg-Ruhrort (20 ma.s.l.) after $219 \mathrm{~km}$. The landscape characteristics of the catchment range from densely wooded and scarcely populated lower mountain ranges in the Sauerland to widely sealed urban areas in the river valleys and in the western part close to the mouth. The area belongs to the geology and geography of the Rhenish Slate Mountains to the east of the Rhine (Brudy-Zippelius, 2003). The average discharge at the confluence with the Rhine is about $80.5 \mathrm{~m}^{3} \mathrm{~s}^{-1}$ (Bode et al., 2003). With a total of eight dams and five reservoirs the Ruhr and its tributaries form a complex hydrological system. The total stored water surface area of about $35 \mathrm{~km}^{2}$ equates to about 480 million $\mathrm{m}^{3}$ of water retained behind damming structures (Ruhrverband, 2011). An intensive use of water resources (e.g. reservoirs, 

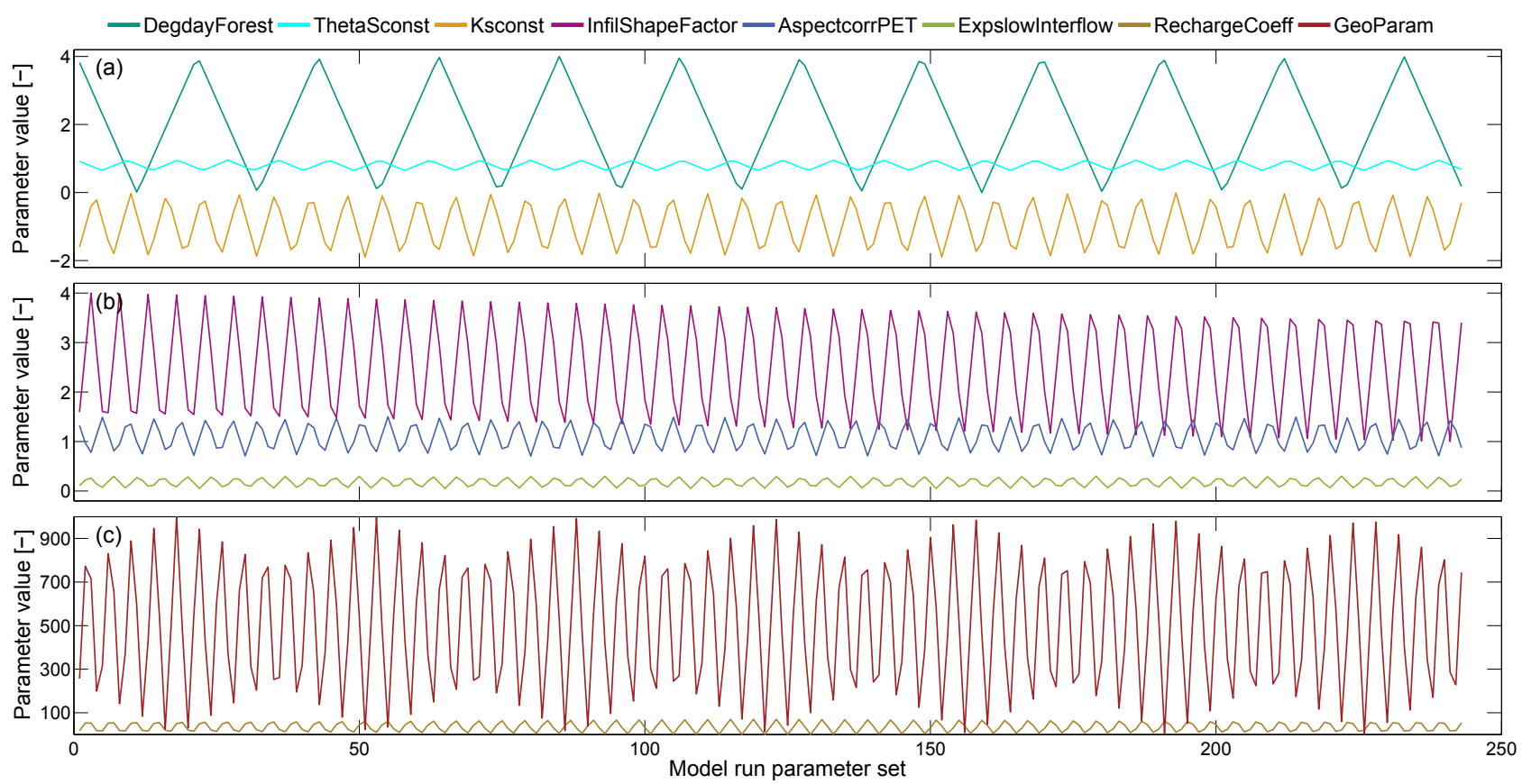

Figure 2. (a-c) Variations of the eight selected global mHM parameters for 243 model runs with independent frequencies according to the FAST sampling plotted as connected curves (see also Table 2).

barrages, withdrawals, inlets) supplies almost 5 million people with drinking and processing water along the Ruhr, within its catchment and to adjacent watersheds.

Our investigations concentrate on 14 headwater catchments (Fig. 1) of the Ruhr River and its tributaries (e.g. Bigge, Lenne, and Möhne), where the hydrological regimes are much less affected by water management measures. The headwaters are situated in the eastern, rural part of the Ruhr basin with higher altitudes, and cover an area of $1742 \mathrm{~km}^{2}$ in total. Individual catchment sizes range from $28.7 \mathrm{~km}^{2}$ at gauge Amecke (AME) to $453.1 \mathrm{~km}^{2}$ at gauge Bamenohl (BAM). Average catchment slopes vary between $10.8 \%$ (Rüblinghausen, RUE) and 26.1\% (Kickenbach, KIC). The dominant form of land cover is forest (39.7-87.3\%) followed by pasture $(0.8-47.5 \%)$, cropland $(7.6-43.9 \%)$ plus a few predominantly dispersed settlements $(0.0-13.2 \%$; Table 3$)$. The climatic conditions are humid warm-temperate (Göppert et al., 1998) with warm summers and moderate winters. Annual mean temperature ranges between 8.45 and $5.45^{\circ} \mathrm{C}$ at the lower and higher altitudes in the study area, respectively. Annual precipitation ranges from $1025 \mathrm{~mm}$ in the northeast to $1425 \mathrm{~mm}$ in the southwest (1997-2006; Table 3).

\subsubsection{Data}

Different kinds of observation data were used to set up and calibrate the hydrological model, to perform simulations for sensitivity analysis, and to derive the fingerprint metrics and a set of physiographic catchment descriptors.
Meteorological input data were daily values for precipitation (HYRAS; Rauthe et al., 2013), temperature (HYRAS; Frick et al., 2014), and potential evapotranspiration (AMBAV; Löpmeier, 1994), all at a spatial resolution of $1 \mathrm{~km}^{2}$. Streamflow observations were available for all headwater catchments from 2002 to 2006. Spatial physiographic data were a digital elevation model $(50 \mathrm{~m} \times 50 \mathrm{~m})$, CORINE land cover data $(100 \mathrm{~m} \times 100 \mathrm{~m}$; European Environment Agency, 2009), a soil map $(1: 200000$; Bundesanstalt für Geowissenschaften und Rohstoffe, 2015a), and a geological map (1: 1000 000; Bundesanstalt für Geowissenschaften und Rohstoffe, 2015b).

A set of 14 descriptors to characterise the hydroclimatic and physiographic setting of the headwaters and to capture characteristics that might jointly control relevant hydrological functions as defined by Black (1997) has been compiled in Table 3. Each descriptor in Table 3 was assigned to one of five main classes of catchment characteristics, i.e. climate (1), landform (2), topography (3), land cover (4), and soil (5), as proposed by Yadav et al. (2007). The choice of climate and physiographic descriptors originates from correlation analysis of catchment descriptors within each category (Yadav et al., 2007), multivariate statistical analysis techniques (Di Prinzio et al., 2011), regionalisation models (Plate et al., 1988), GIS-based analysis of the digital elevation model and, in the case of the baseflow index (BFI), from comparison of methods for baseflow separation (Duband et al., 1993). Table 3 includes the BFI as an intermediate form between physiographic descriptors of soil hydrological 
Table 3. Physiographic and climate descriptors characterising the topographic and hydroclimatic (1997-2006) setting of 14 Ruhr headwater catchments.

\begin{tabular}{|c|c|c|c|c|c|c|c|c|c|c|c|c|c|c|c|c|c|}
\hline \multirow[t]{2}{*}{ Characteristic } & \multirow[t]{2}{*}{ Descriptor } & \multirow[t]{2}{*}{ Abbreviation } & \multirow[t]{2}{*}{ Unit } & \multicolumn{14}{|c|}{ Headwater } \\
\hline & & & & NIC & VOE & MOE & AME & BOE & RUE & HUE & OLP & KRA & KIC & HER & BAM & WEN & MES \\
\hline \multirow[t]{2}{*}{ (1) Climate } & Wetness index & $\mathrm{P} / \mathrm{PET}$ & $(-)$ & 2.3 & 2.1 & 2.1 & 2.4 & 2.5 & 2.2 & 2.3 & 2.2 & 2.2 & 2.4 & 2.3 & 2.3 & 2.2 & 2.5 \\
\hline & Annual precipitation & PMEAN & $(\mathrm{mm})$ & 1170 & 1025 & 1062 & 1240 & 1425 & 1286 & 1334 & 1232 & 1263 & 1261 & 1278 & 1237 & 1156 & 1192 \\
\hline \multirow[t]{2}{*}{ (2) Landform } & Area & A & $\left(\mathrm{km}^{2}\right)$ & 37 & 293 & 66 & 29 & 48 & 86 & 47 & 35 & 38 & 187 & 61 & 453 & 184 & 426 \\
\hline & Longest drainage path & LDP & $(\mathrm{km})$ & 13 & 44 & 16 & 10 & 13 & 19 & 9 & 10 & 13 & 36 & 13 & 52 & 21 & 39 \\
\hline \multirow[t]{5}{*}{ (3) Topography } & Slope & SLOPE & $(\%)$ & 22.6 & 10.9 & 11.2 & 17.3 & 14.9 & 10.8 & 13.2 & 17.5 & 16.0 & 26.1 & 21.1 & 22.5 & 16.2 & 20.9 \\
\hline & Weighted slope & $I_{g}$ & $(\%)$ & 1.7 & 0.5 & 1.1 & 2.1 & 0.9 & 0.5 & 0.8 & 1.2 & 0.9 & 0.7 & 1.6 & 0.5 & 0.6 & 0.7 \\
\hline & Elevation range & ELR & (m) & 430 & 426 & 316 & 361 & 297 & 394 & 204 & 274 & 391 & 533 & 415 & 425 & 440 & 585 \\
\hline & Aspect & ASP & $\left({ }^{\circ}\right)$ & 195 & 189 & 187 & 189 & 167 & 175 & 170 & 197 & 159 & 201 & 199 & 188 & 186 & 190 \\
\hline & Flow accumulation & FACC & $\left(\mathrm{km}^{-1}\right)$ & 0.7 & 0.3 & 0.6 & 0.7 & 0.6 & 0.5 & 0.5 & 0.7 & 0.9 & 0.5 & 0.5 & 0.2 & 0.3 & 0.2 \\
\hline \multirow[t]{4}{*}{ (4) Land cover } & Forest & FOR & $(\%)$ & 55 & 50 & 87 & 51 & 54 & 43 & 40 & 62 & 52 & 72 & 75 & 67 & 41 & 60 \\
\hline & Urban area & URB & (\%) & 0 & 7 & 1 & 3 & 2 & 13 & 5 & 7 & 4 & 4 & 3 & 6 & 3 & 5 \\
\hline & Pasture & PAST & $(\%)$ & 21 & 13 & 2 & 20 & 8 & 26 & 48 & 6 & 1 & 15 & 6 & 10 & 16 & 10 \\
\hline & Cropland & CROP & $(\%)$ & 24 & 29 & 10 & 26 & 36 & 18 & 8 & 25 & 44 & 9 & 17 & 17 & 40 & 24 \\
\hline (5) Soil & Baseflow index & BFI & $(-)$ & 0.39 & 0.34 & 0.33 & 0.38 & 0.37 & 0.38 & 0.39 & 0.39 & 0.42 & 0.35 & 0.36 & 0.34 & 0.34 & 0.31 \\
\hline
\end{tabular}

characteristics and temporally aggregated fingerprint metrics introduced in Sect. 2.1.

\section{Results}

\subsection{Temporal dynamics of parameter sensitivity (TEDPAS)}

TEDPAS analysis for the 14 headwaters in the period of 1997-2006 showed a strong temporal dependence of the fraction of the total variance explainable by first-order sensitivities for hydrograph simulation. The sum of all eight parameter sensitivity values per time step ranged between 0.26 and 0.87 , while the average sum of the eight sensitivity values per time step was 0.71 . The spread between the maximal and minimal sum per time step was found to be smaller in the southwestern (e.g. Rüblinghausen RUE, 0.48) than in the northeastern (e.g. Völlinghausen VOE, 0.61) headwaters.

Minimal and maximal (sensitivity range) and the average (sensitivity mean) sensitivity values of the eight parameters, summarised across all headwaters (Table 2), give a first impression that the soil moisture parameter Ksconst generally exhibited the highest influence (sensitivity mean 0.392), while AspectcorrPET showed the largest range (sensitivity range 0-0.78). The interflow parameter ExpslowInterflow had the smallest sensitivity range $(0-0.22)$, whereas parameters for snow (DegdayForest) and baseflow (GeoParam) had the overall lowest sensitivity mean values of 0.012 . Across all headwaters, the parameters listed in terms of their average sensitivity to streamflow simulations are (in descending order): Ksconst, AspectcorrPET, ExpslowInterflow, RechargeCoeff, ThetaSconst, InfilShapeFactor, GeoParam, and DegdayForest.

TEDPAS did not reveal many differences between the headwaters. For instance, Ksconst consistently had a highly dynamic course of sensitivity with frequently high values (Fig. 3a and b). Nevertheless, some of the parameters showed differences between the headwaters, for example for DegdayForest (January-March; Fig. 3a and b) and AspectcorrPET (November-April; Fig. 3c and d). AspectcorrPET allows us to include the aspect of slopes, controlling insulation, in evapotranspiration estimations, while DegdayForest is a parameter related to snow dynamics in forested areas.

The example of these two parameters also illustrates the seasonality in sensitivity dynamics. AspectcorrPET showed highest sensitivity in the summer period from April to August, when evapotranspiration processes dominate and streamflow dynamics are low (Fig. 3c and d, g and h). During that period, the parameter showed an alternating course of sensitivity compared to Ksconst (Fig. 3b and d) with local maxima connected to (simulated) streamflow peaks (Fig. 3h).

Higher sensitivities of DegdayForest were found for periods (e.g. February) when snow processes (accumulation and melting) can occur. This was predominantly observed in catchments at higher altitudes - for example, for the headwater VOE (up to $630 \mathrm{~m}$ a.s.l.) rather than for RUE ( $450 \mathrm{~m}$ a.s.l.; Fig. 3a and b). Also, VOE (50\%) exhibits a higher percentage of forest cover (FOR) than RUE (43\%; Table 3). A similar distinction between summer and winter patterns was found for InfilShapeFactor, although at lower sensitivity levels (Fig. 3c and d). For the rest of the parameters either no seasonal patterns (e.g. RechargeCoeff; Fig. 3e and f) could be seen or only very low sensitivity values were found (e.g. ThetaSconst; Fig. 3a and b).

The ensembles of simulated streamflow compared reasonably well with the observed hydrographs (Fig. $3 \mathrm{~g}$ and h), although the simulation ensemble underestimated some highflow periods.

\subsection{Sensitivity duration}

SDCs for the 14 headwaters revealed distinct influences of the eight parameters on streamflow simulations (Fig. 4). Different sensitivity characteristics were identifiable among 

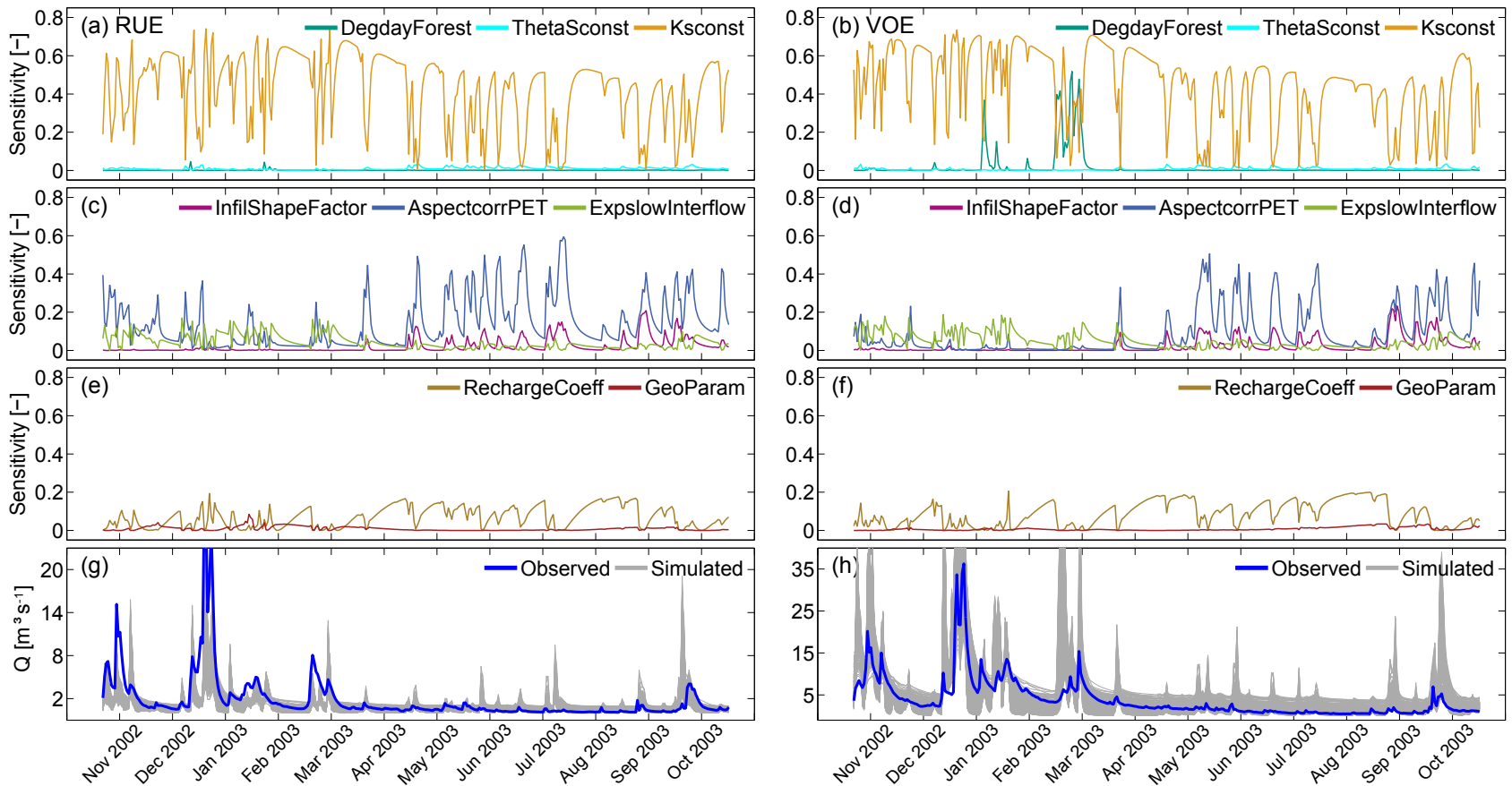

Figure 3. Time-dependent FAST sensitivities (TEDPAS) of eight global mHM parameters for two headwater gauges RUE (a, c, e) and VOE (b, d, f), and observed and FAST-mHM simulated streamflow ensembles at gauges RUE (g) and VOE (h). The results are shown for the hydrological year 2003 consisting of a wet season (November 2002-March 2003) and a long dry period from April 2003 to September 2003. Please note the different axis scaling for streamflow for the two headwaters $(\mathbf{g}, \mathbf{h})$.

the parameters, with either very low (e.g. DegdayForest; Fig. 4a and ThetaSconst; Fig. 4b), intermediate (RechargeCoeff; Fig. 4g) or high (Ksconst; Fig. 4c) influence with respect to sensitivity exceedance probability.

Some of the parameters showed a regional variation of SDCs. Four of eight parameters, i.e. Ksconst (Fig. 4c), InfilShapeFactor (Fig. 4d), AspectcorrPET (Fig. 4e), and ExpslowInterflow (Fig. 4f), revealed certain differences among the headwaters. The SDCs of the two most influential parameters Ksconst (Fig. 4c) and AspectcorrPET (Fig. 4e) showed a systematic spread for the different headwaters, with the curve of gauge RUE plotting at the lower (Fig. 4c) and upper (Fig. 4e) margins of the group of headwaters, respectively. For InfilShapeFactor (Fig. 4d), the headwater MöhneseeNeuhaus (MOE), and for ExpslowInterflow (Fig. 4f) both RUE and MOE deviated from the other headwaters and showed lower SDC values.

In the case of AspectcorrPET (Fig. 4e), the SDCs were sorted from the southwestern (e.g. RUE) to the northeastern (e.g. MES) headwaters (Fig. 1). In the southwestern headwaters (e.g. RUE) the slopes are gentler with lower relief energy than further northeast, where valleys are more deeply incised (e.g. NIC, SLOPE and ELR; Table 3). The slopes in the southwestern headwaters are on average facing southeast, compared to the more southwest-facing slopes in the northern and eastern Ruhr headwaters (ASP; Table 3). Besides showing a different aspect, the southwestern headwater RUE also has the highest proportion of urban areas (URB, $13 \%$; Table 3). Both factors influence the estimation of evapotranspiration in $\mathrm{mHM}$ and hence streamflow simulations.

The SDCs of the most sensitive parameter Ksconst (Fig. 4c) showed concave curvatures, in contrast to the other parameters which had convex SDCs. The SDCs of the largest headwater Bamenohl (BAM) fell in between the other catchments, showing a kind of transitional behaviour of sensitivity duration (Fig. 4), except for ExpslowInterflow.

\subsection{Parameter sensitivity to fingerprints (INDPAS)}

\subsubsection{Single-value indices}

Similar patterns of parameter sensitivities to single-value fingerprints were consistently found across all 14 headwaters. Figure 5 shows the matrix representations for four representative headwaters (RUE, VOE, HER, and WEN). All of them comprise eight rows for the parameters and eight columns for the fingerprint metrics. Sensitivity to a specific fingerprint is arranged column-wise.

As in the TEDPAS analysis, Ksconst was by far the most sensitive parameter for the simulation of five of the fingerprints (CV, HPC, HFD, BFI, RTC) in all 14 headwater catchments. The parameters ExpslowInterflow and RechargeCoeff were identified as the second and the third most sensitive parameter in these cases. In terms of the fingerprint RR, in con- 


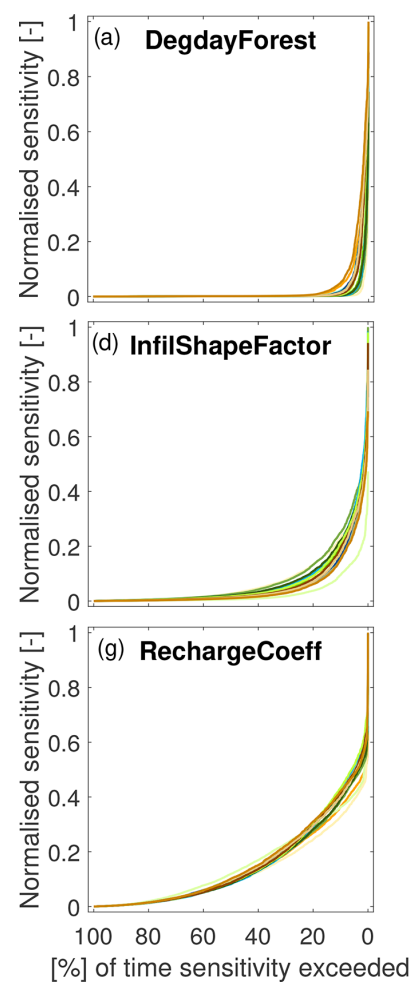

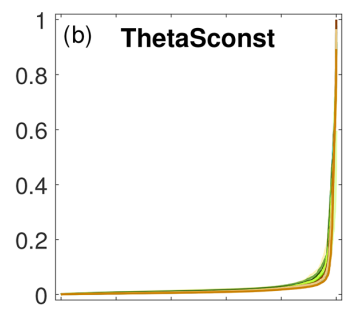
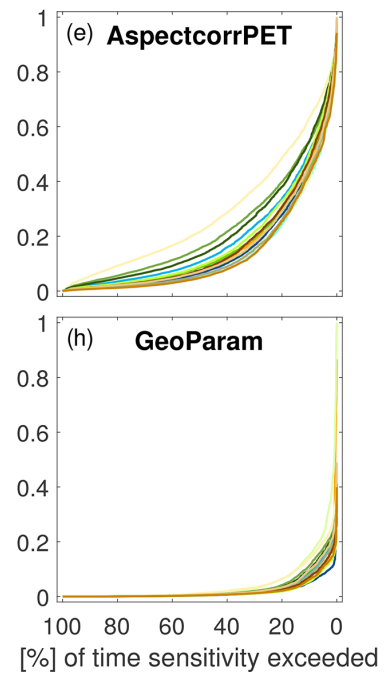
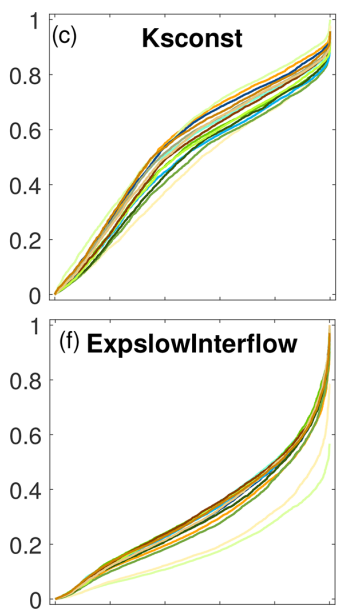

[\%] of time sensitivity exceeded

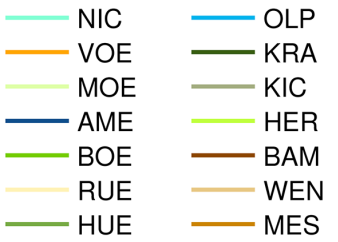

Figure 4. Sensitivity duration curves (SDCs) for eight global mHM parameters of 14 Ruhr headwater catchments (1997-2006): DegdayForest (a), ThetaSconst (b), Ksconst (c), InfilShapeFactor (d), AspectcorrPET (e), ExpslowInterflow (f), RechargeCoeff (g), and GeoParam (h). SDCs are shown normalised by the highest sensitivity value for each parameter among the headwaters. The eight parameters in terms of their average importance to streamflow simulations (TEDPAS) among all headwaters listed in descending order: Ksconst, AspectcorrPET, ExpslowInterflow, RechargeCoeff, ThetaSconst, InfilShapeFactor, GeoParam, and DegdayForest.

trast, AspectcorrPET was the most sensitive parameter, while others, including Ksconst, showed almost no sensitivity to the simulation of the overall water balance. The parameters RechargeCoeff and Ksconst had similarly highest importance for the simulation of the fingerprint SLFDC (slope of the flow duration curve). Other parameter-fingerprint combinations revealed parameters with very low sensitivity values, e.g. DegdayForest or GeoParam, which showed very low sensitivities to all of the eight fingerprint metrics (Fig. 5).

Only minor differences in these patterns occurred between the catchments, and these related to small deviations in absolute sensitivity values or in the order of the second and third rank, e.g. for the fingerprint ACT (Fig. 5).

\subsubsection{Flow duration curve}

Using FDCs as model response targets revealed parameter sensitivities to different streamflow magnitudes. Again, a high proportion of similarities among the headwaters was found. The highest influence was alternately exerted by the parameters Ksconst and AspectcorrPET (Fig. 6a-d); their courses of parameter sensitivity were highly anticorrelated (mean correlation across all headwaters $r=-0.975$ ). The soil moisture parameter Ksconst clearly dominated the very high flows (0-10\% of time $Q$ is exceeded) and the entire mid- and low-flow sections (40-100\%); moderate high flows between 10 and $40 \%$ were most affected by changes in the evapotranspiration parameter AspectcorrPET. These changes in the dominating parameter are additionally illustrated in Fig. 6 by a catchment-specific strip showing the pattern of parametric dominance along the FDC, which showed only slight differences in the lengths of the intermittent parts (AspectcorrPET) between the headwaters.

The other parameters reached overall lower sensitivity levels. The patterns were again similar for all headwaters, with minor differences regarding the absolute sensitivity values and the order of importance in the third and higher ranks. The parameters RechargeCoeff and ExpslowInterflow revealed a bimodal sensitivity distribution. RechargeCoeff showed a first peak between 0 and $20 \%$, and a steady increase from $40 \%$ to its maximum sensitivity value at very low flows with $100 \%$ of streamflow exceedance, which was a sensitivity value of about 0.25 in the case of gauge HER (Fig. 6c). ExpslowInterflow had its highest parametric influence at very high flows (0-15\%), and at moderate- to low-flow magnitudes. The curves of InfilShapeFactor alternated with ExpslowInterflow along the FDCs (Fig. 6a-d), while the rest of the parameters did not show notable sensitivity values. 

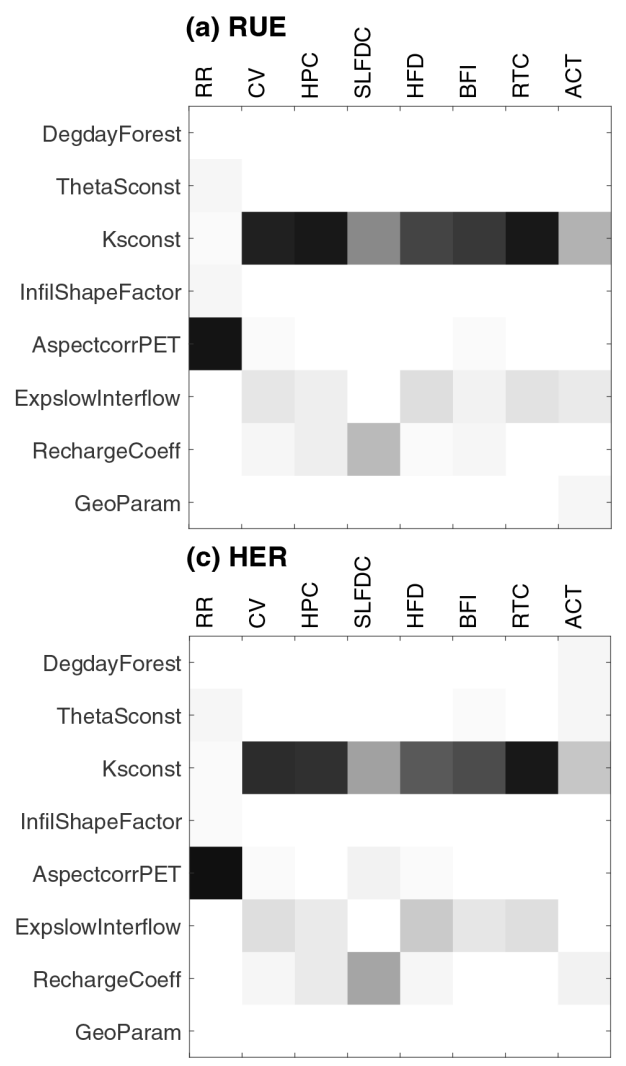
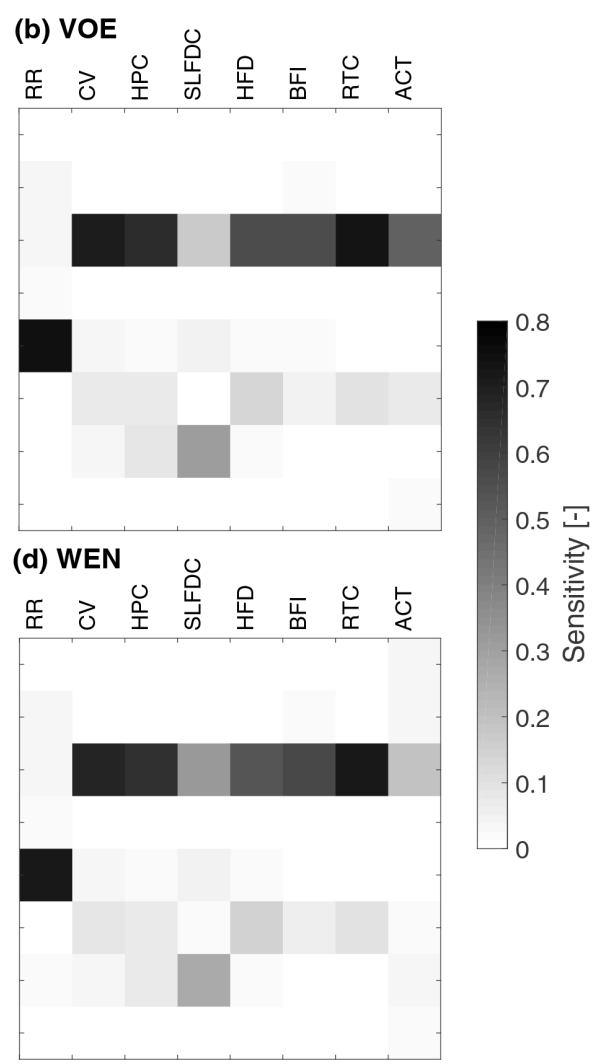

Figure 5. Sensitivity of eight global mHM parameters to eight single-value fingerprint metrics (RR, CV, HPC, SLFDC, HFD, BFI, RTC, ACT) in four Ruhr headwater catchments: RUE (a), VOE (b), HER (c), WEN (d). The simulation period was 1997 to 2006.

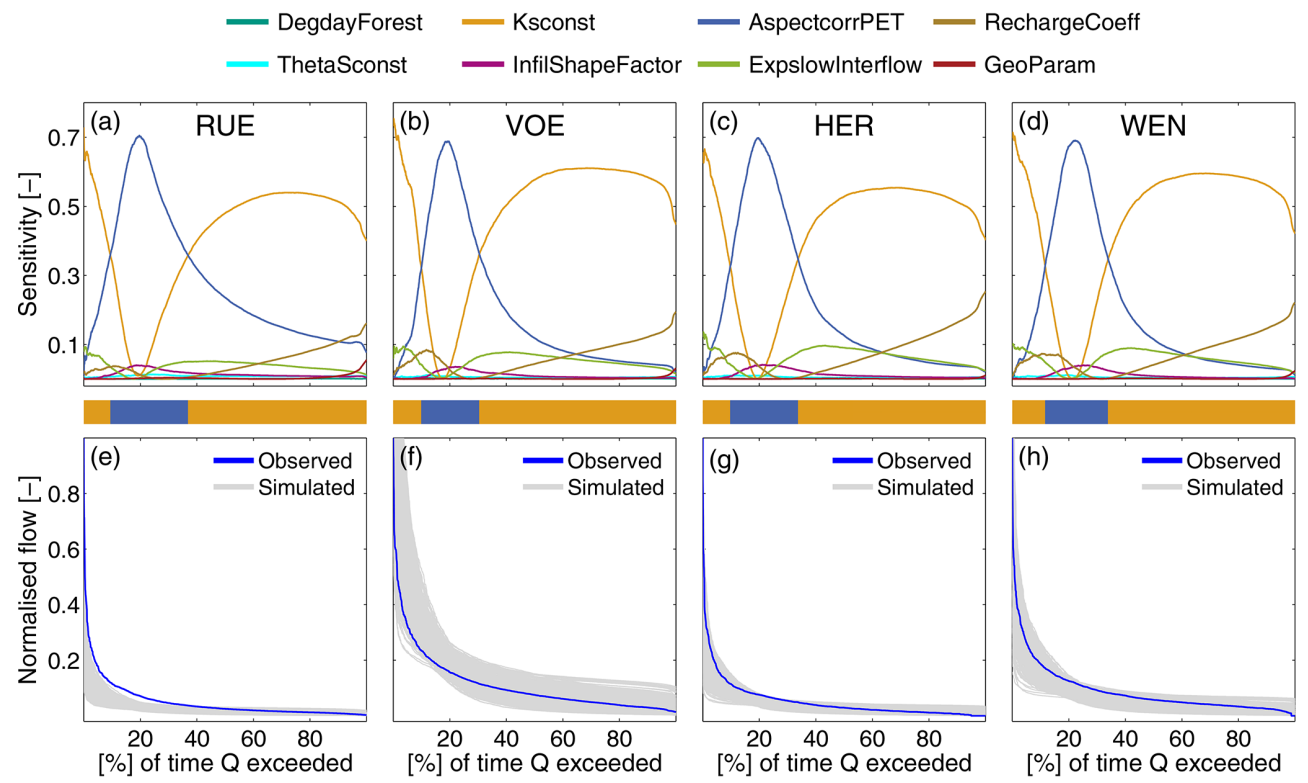

Figure 6. (a-d) Sensitivity of eight global mHM parameters along streamflow exceedance probability (flow duration curve, FDC) for four Ruhr headwater catchments RUE, VOE, HER, and WEN. Catchment-specific strips show the parameters with the highest sensitivity along the FDC. (e-h) Observed flow duration curves and the corresponding ensembles of each 243 simulated FDCs for the period 2002 to 2006 , normalised by the highest streamflow value observed at each of the four headwater gauges. 
Interestingly, the ensembles of normalised FDCs showed distinct differences between the catchments (Fig. 6e-h), although the sensitivity dynamics were similar, and the same 243 parameter variations from FAST were used for each headwater. The largest spread of FDCs was found for the northeastern headwater VOE (Fig. 6f) with the largest catchment size among the four shown headwaters. The smaller headwaters WEN, HER, and RUE (Fig. 1) showed a decreasing spread of the FDCs from northeast to southwest (Fig. 6h, $\mathrm{g}, \mathrm{e})$. Additionally, the widths of the simulation envelopes changed for different streamflow magnitudes. All ensembles of FDCs showed a constriction point located at about $20 \%$ of streamflow exceedance (Fig. 6e-h), which is the same point where Ksconst and AspectcorrPET showed lowest and highest sensitivity values, respectively (Fig. 6a-d). The ensembles of simulated FDCs encompassed the observed FDC in most cases (e.g. VOE, HER, WEN; Fig. 6f-h). In some cases the observed FDC was outside the simulated range (e.g. RUE; Fig. 6e).

\section{Discussion}

\subsection{Parameter sensitivities from TEDPAS and INDPAS}

The combination of TEDPAS and INDPAS created a detailed sensitivity pattern for the response characteristics of the hydrological model mHM. Overall, the soil moisture dynamics parameter Ksconst and the evapotranspiration parameter AspectcorrPET were found most relevant for the simulation of the streamflow response of 14 Ruhr headwaters.

The TEDPAS analysis confirmed, as expected, a seasonality of sensitivity for parameters controlling snow (DegdayForest) or evapotranspiration (AspectcorrPET) processes. More interestingly, TEDPAS also showed an alternating dominance of Ksconst and AspectcorrPET during the temporal course of the simulation. Using flow duration curves as response targets (INDPAS) clarified that this was related to different streamflow magnitudes. The soil moisture dynamics (Ksconst) dominated at both high and low flows, which may be attributed to the dual role of Ksconst in parameterising both storage (field capacity) and transmission (conductivity) of soil water in mHM. During intermediate-flow conditions, evapotranspiration (AspectcorrPET) governed the streamflow simulations, probably because of the high influence of evapotranspiration on the shallow soil storage and thus the system state of the catchment. This high sensitivity of an evapotranspiration parameter during intermediate-flow conditions coincides with the findings of former studies (e.g. Guse et al., 2014, 2016b).

The specific influence of AspectcorrPET was mainly on the water balance (fingerprint RR) in all of the headwaters. Ksconst was the most sensitive parameter for most of the other single-value fingerprints, encompassing those quantifying low-flow (BFI) as well as high-flow conditions or the flashiness of hydrological response (CV, HPC, HFD, RTC). Only for one single-value fingerprint (SLFDC, related to the rate of change in streamflow) another parameter (RechargeCoeff) was found to be as sensitive as Ksconst. The moderate relevance of the groundwater-related RechargeCoeff increased during low-flow periods, as illustrated by INDPAS using FDCs and TEDPAS.

A temporally resolved sensitivity makes it difficult to reveal clear patterns of dominant parameters when dealing with long time periods. Guse et al. (2016b) also recognised that parameter sensitivity by TEDPAS based on the streamflow hydrograph should be analysed on different temporal aggregation levels and should be related to different streamflow magnitudes for a detailed assessment of dominant model parameters and temporal process dynamics. While their methodological approach was purely based on aggregation and reordering of TEDPAS sensitivity and streamflow time series, we added additional value with INDPAS aiming at multiple response targets including FDCs. The consideration of flow duration curves enabled analysing streamflow free of autocorrelation and time dependence. The FDC as a model response target for sensitivity analysis provided information on parameter sensitivity along the independent variable of streamflow exceedance probability. In contrast, for classical hydrograph inspection, which is the basis of TEDPAS, time is the independent variable. INDPAS along FDCs allowed us to draw conclusions about parametric influences at specific streamflow magnitudes.

Regardless of the chosen model response target, in the case of 14 Ruhr headwaters only one or a very small group of parameters were identified as relevant for streamflow response. In this context, Herman et al. (2013) showed that the longterm water balance is dominated by only very few parameters, irrespective of the hydrological conditions and of the model. Cuntz et al. (2015) performed a global Sobol sensitivity analysis on the hydrologic model mHM. For three distinct humid and arid European catchments this analysis always resulted in about 20 informative parameters, though the dominant parameter sets were composed very differently. Their criteria to select the sensitive parameters was substantially different from our approach, which renders a direct comparison between the studies difficult. The different number of dominant parameters might also be due to correlated mHM parameters which we sorted out before sensitivity analysis. In contrast, Cuntz et al. (2015) considered the degree of correlation between $\mathrm{mHM}$ parameters as rather minor to be interfering with parameter identification.

Especially the application of fingerprints as model response targets for sensitivity analysis revealed further details of parametric dominance that can help in more directed model applications. Dominant parameters can be additionally adjusted pinpointed to fingerprint metrics in a subsequent calibration step, while insensitive parameters can be disregarded for model calibration directed to the respective response target (van Werkhoven et al., 2009). This reduces 
the parameter space and need for constraining parameter values and thus facilitates model calibration. A missing sensitivity signal to a fingerprint (e.g. RechargeCoeff to RR) can reveal that the chosen response target might not be relevant to further constrain the parameter identification in a certain catchment.

The spread of the simulated response ensembles allows us to judge whether a fingerprint metric is a reliable response target for sensitivity analysis or whether different fingerprints, e.g. the master recession curve or the double mass curve, should be considered instead. For example, the hydrographs and FDCs showed significant spread that also differed between the catchments (Figs. 3 and 6). In contrast, the spread in simulated values for the Autocorrelation Time (ACT) was small for all catchments. Accordingly, INDPAS analysis directed to ACT also showed only moderate sensitivities for the set of eight parameters (Fig. 5). Our preselection of eight parameters can potentially lead to the elimination of other storage parameters that might be most sensitive to ACT. Thus, one might conclude that parameter selection based on INDPAS would result in a different choice in the set of the most sensitive parameters. In the case of ACT this is not very likely, since storage parameters (e.g. ExpslowInterflow and GeoParam) were still included. Instead, the precipitation time series has a large impact on the autocorrelation structure of streamflow; the ACT metric is thus less informative than others that depend less on the hydroclimatic boundary conditions.

The resulting partial variances for each fingerprint are comparable as they portray the relative influence of the parameters on the variation of the target, regardless of the specific values of the targets. In order to take into account the impact of the spread of the simulation results on the parameter sensitivities, a weighting factor for partial parameter sensitivities might be helpful. An impact-weighted INDPAS might then be used along with catchment class-specific response fingerprints to select relevant parameters for the specific hydrological conditions. In Fig. 6 we normalised the FDCs by the maximum value of each time series. For the visual comparison of sites this is a necessary step, but it might lead to a different form of appearance, including the spread of the simulation ensemble. If absolute fingerprint values are replaced by normalised quantities (Samaniego et al., 2010a; He et al., 2011), dimensions should be considered explicitly when determining sensitivity weighting factors.

Our findings using different model response targets confirm the necessity of a multivariate sensitivity analysis. This was similarly recognised by Wagener et al. (2009), who applied three standard error metrics as objective functions for sensitivity analysis. Their results for parameter sensitivity were found to change spatially when the objective function was replaced. Razavi and Gupta (2015) similarly pointed out that even conflicting conclusions could be drawn if different properties of the model response were applied in sensitivity analysis. To avoid misinterpretation of sensitivity results we propose that the selection of specific fingerprint metrics should be determined by the purpose of the modelling; for instance, sensitivity to fingerprint metrics for peak flow is suitable if flood prediction is the focus. Redundancy is not problematic if several similar metrics for a specific streamflow characteristic are selected, e.g. HPC, CV, and HFD for high flows. A multivariate analysis with metrics of several, even partly similar streamflow characteristics (frequency of high flow, magnitude of high flows etc.) is rather helpful to ensure complete parameter identification for different catchments. Aggregated and temporally independent fingerprints like the FDC proved to be especially applicable.

\subsection{Regional differences in parameter sensitivity}

Although the most sensitive parameters and the corresponding sensitivity patterns of streamflow response were found to be similar for the 14 investigated Ruhr headwater catchments, the analysis with TEDPAS and INDPAS revealed certain regional differences.

Especially the analysis of sensitivity duration curves derived from TEDPAS revealed regional differences of parameter sensitivity between headwaters. For half of the eight selected parameters we found regional differences in SDCs (Sect. 3.2 and Fig. 4). The most sensitive parameters exhibited the largest spread of SDCs (e.g. Ksconst and AspectCorrPET; Fig. 4c and e), and their SDCs were systematically ordered according to the geographical location (southwestnortheast) and the physiographic setting (ASP, URB; Table 3). Some catchments deviate from the general pattern in SDCs for evapotranspiration and interflow parameters (e.g. RUE; Fig. 4e and $\mathrm{f}$ ). In these cases, the specific combination of catchment characteristics (degree of soil sealing, topographic gradients, land cover) might have led to different processes in streamflow simulations. For the catchment of RUE, the smallest slope value among the headwaters in conjunction with the highest percentage of urban area (SLOPE, URB; Table 3) can explain the deviation from the general pattern of SDCs for the two parameters. SDCs thus provided a convenient means to identify regionally different sensitivity characteristics for each of the analysed parameters.

The results from the INDPAS analysis directed to singlevalued fingerprints also showed some differences between the headwaters. In particular, the sensitivity patterns of the second and third ranked parameters were found to differ, although not with the same systematic ordering as for the SDCs. The patterns of the most sensitive parameters along streamflow exceedance probability (catchment-specific strips in Fig. 6) provided visually condensed diagnostic information for different streamflow magnitudes, but showed only minor differences between the catchments.

Together this shows that even the small physiographic gradients in the Ruhr headwater catchments can cause differences in parameter sensitivity to streamflow response characteristics. This finding is partly contrary to those of Guse et al. 
(2014), who reported almost no differences of parameter sensitivities among different subcatchments of the Treene in northern Germany in a similar analysis. This was explained by the absence of a pronounced heterogeneity in their study area.

Given that the same parameter sets are applied to all headwater catchments, any regional differences in parameter sensitivity originate from differences either in the hydroclimatic or in the physiographic setting. In the case of the Ruhr headwaters, the local hydroclimatic and physiographic differences (Table 3) seem to be sufficient to be discriminated by the hydrological model structure in the form of a different variation in streamflow response. Due to their geographical proximity, the 14 Ruhr headwaters are generally similar in terms of the long-term hydroclimate (Wetness Index) and the physiography, e.g. in their soil hydrological characteristics (BFI). They show, however, some differences in annual precipitation amount, topographic gradient, and land cover. The average annual precipitation in the simulation period between 1997 and 2006 reveals a hydroclimatic gradient with lower to higher precipitation rates from northeast to southwest (PMEAN), similar to the geographical ordering of the SDCs in Fig. 4. Song et al. (2013) also attributed local differences of parameter sensitivity to the spatial distribution of meteorologic forcing. Demaria et al. (2007) similarly concluded that parameter sensitivity was more strongly determined by climate gradients than by changes in soil properties in their Monte Carlo-based sensitivity study. Under different hydrological conditions, regional sensitivity patterns or the number of parameters which influence streamflow simulations might be different from the present example (Cuntz et al., 2015).

As parameter sensitivity is a prerequisite for parameter identifiability, even slight differences in sensitivity reveal information about how identifiability can change among different catchments. Scale-dependent limitations have to be kept in mind to avoid a levelling out of the explanatory value of a physiographic descriptor (Blöschl and Sivapalan, 1995), possibly resulting in an intermediate course of sensitivity duration as seen for the largest headwater of Bamenohl (BAM; Sect. 3.2 and Fig. 4). van Griensven et al. (2006) remarked that local differences indicate that results of global sensitivity analysis for one catchment cannot be directly applied to other, even nearby locations, but may be used as reasonable estimates within the same catchment category. Locations with intermediate-sensitivity characteristics (e.g. BAM) could at least serve as a starting point for parameter transfer to closely located ungauged sites. As the local differences between the Ruhr headwaters are not very large, the most sensitive parameters found for WEN in the first step of the analysis with all model parameters were also dominant in the other subcatchments, which was corroborated by the TEDPAS analysis with eight selected parameters on all subcatchments. Any local differences in parameter sensitivity revealed by the analysis of sensitivity duration or INDPAS could then be handled during individual model calibration for each catchment.

\section{Conclusions}

We used FAST for a global sensitivity analysis of the hydrological model mHM in 14 headwater catchments of the Ruhr River in Germany. Our multilevel approach not only reveals the dominating parameters for streamflow simulation but also pinpoints the influences of the analysed parameters to diverse aspects of hydrological response processes. Especially the application of several hydrological fingerprints as response targets allows for detailed model diagnostics. Comparison of streamflow response characteristics and analysing along the range of streamflow magnitudes shows how the parametric dominances and the most influential parameters can change with streamflow conditions, for example the complementary sensitivity of soil moisture dynamics and evapotranspiration in our case. The combination of TEDPAS and INDPAS also provides a means to unveil the slight differences in catchment-specific patterns between the closely located headwaters. The general similarity in the sensitivity patterns indicates, however, that a parameter transfer to other catchments might be possible, provided that the interplay of catchment structure and local hydroclimate has evolved in a similar way.

The results provide in-depth diagnostics on the model and its parameters, which can support future improvements of model structures, and facilitate case-specific model calibration in a reduced parameter space. The methodological approach of the multilevel sensitivity analysis with fingerprints as response targets may be generalised to any hydrological model or kind of catchment. The findings of this study motivate to include further catchments as regional end-members within different physiographic and climate settings to evaluate how parameter identifiability and the simulated hydrological functioning regionally changes among distant catchments. The consideration of multivariate response variables in diagnostics of hydrological models is beneficial for a complete identification, not only of parameter influences on simulated hydrological functioning but also of the regional relevance for model calibration. 
Data availability. The streamflow data and the digital elevation model used in this study are not publicly accessible, and were provided by the Ruhrverband in Essen.

The further spatial physiographic data can be downloaded from the web: land cover data (https://land.copernicus.eu/ pan-european/corine-land-cover/clc-2006?tab=download); soil data (https://produktcenter.bgr.de/terraCatalog/OpenSearch.do? search=3E80DA1A-A9A7-45A3-9CC7-79796FE9ABA4\&type= /Query/OpenSearch.do); geological data (https:// produktcenter.bgr.de/terraCatalog/DetailResult.do?fileIdentifier= 1C60DDA9-EF73-47B9-9ED7-FCD22B3226C1).

Meteorological input data are available from Deutscher Wetterdienst. Data for precipitation (HYRAS; Rauthe et al., 2013) and temperature (HYRAS; Frick et al., 2014) can be obtained via https://www.dwd.de/DE/leistungen/hyras/hyras.html. The database for potential evapotranspiration (AMBAV; Löpmeier, 1994) can be accessed via ftp://ftp-cdc.dwd.de/pub/CDC/grids_germany/daily/ evapo_p.

Competing interests. The authors declare that they have no conflict of interest.

Acknowledgements. The streamflow data and the digital elevation model used in this study were provided by the Ruhrverband in Essen. We thank Linda Bergmann, who supported the technical implementation of the FAST analysis. We are grateful to Fanny Sarrazin, Sibylle Haßler, Björn Guse, Shervan Gharari, and one anonymous reviewer for their critical comments on this and an earlier version of the manuscript, which greatly helped to improve the paper. We acknowledge support by Deutsche Forschungsgemeinschaft and Open Access Publishing Fund of Karlsruhe Institute of Technology.

The article processing charges for this open-access

publication were covered by a Research

Centre of the Helmholtz Association.

Edited by: Ross Woods

Reviewed by: Björn Guse and Shervan Gharari

\section{References}

Atkinson, S. E., Sivapalan, M., Woods, R. A., and Viney, N. R.: Dominant physical controls on hourly flow predictions and the role of spatial variability: Mahurangi catchment, New Zealand, Adv. Water Res., 26, 219-235, https://doi.org/10.1016/S03091708(02)00183-5, 2003.

Beven, K.: Prophecy, reality and uncertainty in distributed hydrological modelling, Adv. Water Res., 16, 41-51, https://doi.org/10.1016/0309-1708(93)90028-E, 1993.

Beven, K.: How far can we go in distributed hydrological modelling?, Hydrol. Earth Syst. Sci., 5, 1-12, https://doi.org/10.5194/hess-5-1-2001, 2001.

Black, P.: Watershed functions, J. Am. Water Resour. Assoc., 33, 1-11, 1997.
Blöschl, G. and Sivapalan, M.: Scale issues in hydrological modelling: A review, Hydrol. Process., 9, 251-290, https://doi.org/10.1002/hyp.3360090305, 1995.

Bode, H., Evers, P., and Albrecht, D. R.: Integrated water resources management in the Ruhr River Basin, Germany, Water Sci. Technol., 47, 81-86, 2003.

Brudy-Zippelius, T.: Wassermengenbewirtschaftung im Einzugsgebiet der Ruhr : Simulation und Echtzeitbetrieb, $\mathrm{PhD}$ thesis, Universität Karlsruhe (TH), 159 pp., 2003.

Bundesanstalt für Geowissenschaften und Rohstoffe: Bodenübersichtskarte der Bundesrepublik Deutschland 1:200.000 (BÜK200), 2015a.

Bundesanstalt für Geowissenschaften und Rohstoffe: Geologische Karte der Bundesrepublik Deutschland 1:1000000 (GK1000), 2015b.

Castiglioni, S., Lombardi, L., Toth, E., Castellarin, A., and Montanari, A.: Calibration of rainfall-runoff models in ungauged basins: A regional maximum likelihood approach, Adv. Water Res., 33, 1235-1242, https://doi.org/10.1016/j.advwatres.2010.04.009, 2010.

Cibin, R., Sudheer, K. P., and Chaubey, I.: Sensitivity and identifiability of stream flow generation parameters of the SWAT model, Hydrol. Process., 24, 1133-1148, https://doi.org/10.1002/hyp.7568, 2010.

Clark, M. P., McMillan, H. K., Collins, D. B. G., Kavetski, D., and Woods, R. A.: Hydrological field data from a modeller's perspective: Part 2: Process-based evaluation of model hypotheses, Hydrol. Process., 25, 523-543, https://doi.org/10.1002/hyp.7902, 2011.

Cloke, H. L., Pappenberger, F., and Renaud, J.-P.: Multi-Method Global Sensitivity Analysis (MMGSA) for modelling floodplain hydrological processes, Hydrol. Process., 22, 1660-1674, https://doi.org/10.1002/hyp.6734, 2008.

Cukier, R. I., Fortuin, C. M., Shuler, K. E., Petschek, A. G., and Schaibly, J. H.: Study of the sensitivity of coupled reaction systems to uncertainties in rate coefficients. I Theory, J. Chem. Phys., 59, 3873, https://doi.org/10.1063/1.1680571, 1973.

Cukier, R. I., Schaibly, J. H., and Shuler, K. E.: Study of the sensitivity of coupled reaction systems to uncertainties in rate coefficients. III. Analysis of the approximations Theory, J. Chem. Phys., 63, 1140, https://doi.org/10.1063/1.431440, 1975.

Cuntz, M., Mai, J., Zink, M., Thober, S., Kumar, R., Schäfer, D., Schrön, M., Craven, J., Rakovec, O., Spieler, D., Prykhodko, V., Dalmasso, G., Musuuza, J., Langenberg, B., Attinger, S., and Samaniego, L.: Computationally inexpensive identification of noninformative model parameters by sequential screening, Water Resour. Res., 51, 6417-6441, https://doi.org/10.1002/2015WR016907, 2015.

Demaria, E. M., Nijssen, B., and Wagener, T.: Monte Carlo sensitivity analysis of land surface parameters using the Variable Infiltration Capacity model, J. Geophys. Res., 112, 1-15, https://doi.org/10.1029/2006JD007534, 2007.

Di Prinzio, M., Castellarin, A., and Toth, E.: Data-driven catchment classification: application to the pub problem, Hydrol. Earth Syst. Sci., 15, 1921-1935, https://doi.org/10.5194/hess-15-19212011, 2011.

Duband, D., Obled, C., and Rodriguez, J.: Unit hydrograph revisited: an alternate iterative approach to $\mathrm{UH}$ and effec- 
tive precipitation identification, J. Hydrol., 150, 115-149, https://doi.org/10.1016/0022-1694(93)90158-6, 1993.

European Environment Agency: CORINE Land Cover (CLC2006), 2009.

Euser, T., Winsemius, H. C., Hrachowitz, M., Fenicia, F., Uhlenbrook, S., and Savenije, H. H. G.: A framework to assess the realism of model structures using hydrological signatures, Hydrol. Earth Syst. Sci., 17, 1893-1912, https://doi.org/10.5194/hess-171893-2013, 2013.

Farmer, D., Sivapalan, M., and Jothityangkoon, C.: Climate, soil, and vegetation controls upon the variability of water balance in temperate and semiarid landscapes: Downward approach to water balance analysis, Water Resour. Res., 39, 1035, https://doi.org/10.1029/2001wr000328, 2003.

Fontaine, D. D., Havens, P. L., Blau, G. E., and Tillotson, M.: Groundwater Risk Modeling for Pesticides, Weed Technol., 6, 716-724, 1992.

Frey, H. C. and Patil, S. R.: Identification and review of sensitivity analysis methods, Computat. Studies, 22, 553-578, https://doi.org/10.1111/0272-4332.00039, 2002.

Frick, C., Steiner, H., Mazurkiewicz, A., Riediger, U., Rauthe, M., Reich, T., and Gratzki, A.: Central European high-resolution gridded daily data sets (HYRAS): Mean temperature and relative humidity, Meteorol. Z., 23, 15-32, https://doi.org/10.1127/09412948/2014/0560, 2014.

Göppert, H., Ihringer, J., Plate, E. J., and Morgenschweis, G.: Flood forecast model for improved reservoir management in the Lenne River catchment, Germany, Hydrolog. Sci. J., 43, 215242, https://doi.org/10.1080/02626669809492119, 1998.

Gupta, H. V., Sorooshian, S., and Yapo, P. O.: Toward improved calibration of hydrologic models: Multiple and noncommensurable measures of information, Water Resour. Res., 34, 751-763, https://doi.org/10.1029/97WR03495, 1998.

Gupta, H. V., Wagener, T., and Liu, Y.: Reconciling theory with observations: elements of a diagnostic approach to model evaluation, Hydrol. Process., 22, 3802-3813, https://doi.org/10.1002/hyp.6989, 2008.

Gupta, H. V., Clark, M. P., Vrugt, J. A., Abramowitz, G., and Ye, M.: Towards a comprehensive assessment of model structural adequacy, Water Resour. Res., 48, 1-16, https://doi.org/10.1029/2011WR011044, 2012.

Guse, B., Reusser, D. E., and Fohrer, N.: How to improve the representation of hydrological processes in SWAT for a lowland catchment - temporal analysis of parameter sensitivity and model performance, Hydrol. Process., 28, 2651-2670, https://doi.org/10.1002/hyp.9777, 2014.

Guse, B., Pfannerstill, M., Gafurov, A., Fohrer, N., and Gupta, H.: Demasking the integrated information of discharge: Advancing sensitivity analysis to consider different hydrological components and their rates of change, Water Resour. Res., 52, 87248743, https://doi.org/10.1002/2016WR018894, 2016 a.

Guse, B., Pfannerstill, M., Strauch, M., Reusser, D. E., Lüdtke, S., Volk, M., Gupta, H., and Fohrer, N.: On characterizing the temporal dominance patterns of model parameters and processes, Hydrol. Process., 30, 2255-2270, https://doi.org/10.1002/hyp.10764, 2016b.

Hamby, D. M.: A review of techniques for parameter sensitivity analysis of environmental models, Environ. Monit. Assess., 32, 135-154, https://doi.org/10.1007/BF00547132, 1994.
He, Y., Bárdossy, A., and Zehe, E.: A catchment classification scheme using local variance reduction method, J. Hydrol., 411, 140-154, https://doi.org/10.1016/j.jhydrol.2011.09.042, 2011.

Herman, J. D., Reed, P. M., and Wagener, T.: Time-varying sensitivity analysis clarifies the effects of watershed model formulation on model behavior, Water Resour. Res., 49, 1400-1414, https://doi.org/10.1002/wrcr.20124, 2013.

Hogue, T. S., Sorooshian, S., Gupta, H., Holz, A., and Braatz, D.: A Multistep Automatic Calibration Scheme for River Forecasting Models, J. Hydrometeorol., $\quad 1, \quad 524-542, \quad$ https://doi.org/10.1175/15257541(2000)001<0524:AMACSF>2.0.CO;2, 2000.

Kavetski, D. and Clark, M. P.: Ancient numerical daemons of conceptual hydrological modeling: 2. Impact of time stepping schemes on model analysis and prediction, Water Resour. Res., 46, 1-27, https://doi.org/10.1029/2009WR008896, 2010.

Kirchner, J. W.: Getting the right answers for the right reasons: Linking measurements, analyses, and models to advance the science of hydrology, Water Resour. Res., 42, 1-5, https://doi.org/10.1029/2005WR004362, 2006.

Kumar, R., Samaniego, L., and Attinger, S.: The effects of spatial discretization and model parameterization on the prediction of extreme runoff characteristics, J. Hydrol., 392, 54-69, https://doi.org/10.1016/j.jhydrol.2010.07.047, 2010.

Kumar, R., Samaniego, L., and Attinger, S.: Implications of distributed hydrologic model parameterization on water fluxes at multiple scales and locations, Water Resour. Res., 49, 360-379, https://doi.org/10.1029/2012WR012195, 2013.

Löpmeier, F.-J.: Berechnung der Bodenfeuchte und Verdunstung mittels agrarmeteorologischer Modelle, Zeitschrift f. Bewässerungswirtschaft, 29, 157-167, 1994.

Lu, Y. C. and Mohanty, S.: Sensitivity Analysis of a complex, proposed geological waste disposal system using the Fourier Amplitude Sensitivity Test Method, Reliab. Eng. Syst. Safe., 72, 275291, https://doi.org/10.1016/s0951-8320(01)00020-5, 2001.

Massmann, C. and Holzmann, H.: Analysis of the behavior of a rainfall-runoff model using three global sensitivity analysis methods evaluated at different temporal scales, J. Hydrol., 475, 97-110, https://doi.org/10.1016/j.jhydrol.2012.09.026, 2012.

Massmann, C. and Holzmann, H.: Analysing the Sub-processes of a Conceptual Rainfall-Runoff Model Using Information About the Parameter Sensitivity and Variance, Environ. Monit. Assess., 20, 41-53, https://doi.org/10.1007/s10666-014-9414-6, 2015.

Massmann, C., Wagener, T., and Holzmann, H.: A new approach to visualizing time-varying sensitivity indices for environmental model diagnostics across evaluation time-scales, Environ. Modell. Softw., 51, 190-194, https://doi.org/10.1016/j.envsoft.2013.09.033, 2014.

McCuen, R. H.: The role of sensitivity analysis in hydrologic modeling, J. Hydrol., 18, 37-53, https://doi.org/10.1016/00221694(73)90024-3, 1973.

Nossent, J. and Bauwens, W.: Multi-variable sensitivity and identifiability analysis for a complex environmental model in view of integrated water quantity and water quality modeling, Water Sci. Technol., 65, 539-549, https://doi.org/10.2166/wst.2012.884, 2012.

Olden, J. D. and Poff, N. L.: Redundancy and the choice of hydrologic indices for characterizing streamflow regimes, River Res. Appl., 19, 101-121, https://doi.org/10.1002/rra.700, 2003. 
O'Loughlin, F., Bruen, M., and Wagener, T.: Parameter sensitivity of a watershed-scale flood forecasting model as a function of modelling time-step, Hydrol. Res., 44, 334-350, https://doi.org/10.2166/nh.2012.157, 2013.

Pfannerstill, M., Guse, B., Reusser, D., and Fohrer, N.: Process verification of a hydrological model using a temporal parameter sensitivity analysis, Hydrol. Earth Syst. Sci., 19, 4365-4376, https://doi.org/10.5194/hess-19-4365-2015, 2015.

Pianosi, F. and Wagener, T.: Understanding the time-varying importance of different uncertainty sources in hydrological modelling using global sensitivity analysis, Hydrol. Process., 30, 39914003, https://doi.org/10.1002/hyp.10968, 2016.

Plate, E. J., Ihringer, J., and Lutz, W.: Operational models for flood calculations, J. Hydrol., 100, 489-506, 1988.

Poff, N. L., Allan, J. D., Bain, M. B., Karr, J. R., Prestegaard, K. L., Richter, B. D., Sparks, R. E., and Stromberg, J. C.: The Natural Flow Regime: A paradigm for river conservation and restoration N, BioScience, 47, 769-784, https://doi.org/10.2307/1313099, 1997.

Pokhrel, P., Yilmaz, K. K., and Gupta, H. V.: Multiple-criteria calibration of a distributed watershed model using spatial regularization and response signatures, J. Hydrol., 418-419, 49-60, https://doi.org/10.1016/j.jhydrol.2008.12.004, 2008.

Rakovec, O., Kumar, R., Attinger, S., and Samaniego, L.: Improving the realism of hydrologic model functioning through multivariate parameter estimation, Water Resour. Res., 52, 613-615, https://doi.org/10.1002/2016WR019430, 2016.

Rauthe, M., Steiner, H., Riediger, U., Mazurkiewicz, A., and Gratzki, A.: A Central European precipitation climatology Part I: Generation and validation of a high-resolution gridded daily data set (HYRAS), Meteorol. Z., 22, 235-256, https://doi.org/10.1127/0941-2948/2013/0436, 2013.

Razavi, S. and Gupta, H. V.: What do we mean by sensitivity analysis? The need for comprehensive characterization of "global" sensitivity in Earth and Environmental systems models, Water Resour. Res., 51, 3070-3092, https://doi.org/10.1002/2014WR016527, 2015.

Reusser, D. E. and Zehe, E.: Inferring model structural deficits by analyzing temporal dynamics of model performance and parameter sensitivity, Water Resour. Res., 47, W07550, https://doi.org/10.1029/2010WR009946, 2011.

Reusser, D. E., Buytaert, W., and Zehe, E.: Temporal dynamics of model parameter sensitivity for computationally expensive models with the Fourier amplitude sensitivity test, Water Resour. Res., 47, W07551, https://doi.org/10.1029/2010WR009947, 2011.

Rodríguez-Camino, E. and Avissar, R.: Comparison of three land-surface schemes with the Fourier amplitude sensitivity test (FAST), Tellus A, 50, 313-332, https://doi.org/10.3402/tellusa.v50i3.14529, 1998.

Ruhrverband: Ruhrwassermenge 2011, Tech. rep., Ruhrverband, Essen, 2011.

Saltelli, A. and Bolado, R.: An alternative way to compute Fourier amplitude sensitivity test (FAST), Comput. Stat. Data An., 26, 445-460, https://doi.org/10.1016/S0167-9473(97)00043-1, 1998.

Saltelli, A., Ratto, M., Andres, T., Campolongo, F., Cariboni, J., and Saisana, M.: Global Sensitivity Analysis. The Primer, John Wiley \& Sons, Ltd., 2008.
Samaniego, L., Bárdossy, A., and Kumar, R.: Streamflow prediction in ungauged catchments using copula-based dissimilarity measures, Water Resour. Res., 46, W02506, https://doi.org/10.1029/2008WR007695, 2010a.

Samaniego, L., Kumar, R., and Attinger, S.: Multiscale parameter regionalization of a grid-based hydrologic model at the mesoscale, Water Resour. Res., 46, 1-25, https://doi.org/10.1029/2008WR007327, 2010b.

Samaniego, L., Kumar, R., and Jackisch, C.: Predictions in a datasparse region using a regionalized grid-based hydrologic model driven by remotely sensed data, Hydrol. Res., 42, 338-355, https://doi.org/10.2166/nh.2011.156, 2011.

Samaniego, L., Cuntz, M., Craven, J., Dalmasso, G., Kumar, R., Mai, J., Musuuza, J., Prykhodko, V., Schneider, C., Spieler, D., Thober, S., and Zink, M.: multiscale Hydrologic Model mHMDocumentation for version 5.1., Tech. rep., Helmholtz Centre for Environmental Research - UFZ, 2014.

Sanadhya, P., Gironás, J., and Arabi, M.: Global sensitivity analysis of hydrologic processes in major snow-dominated mountainous river basins in Colorado, Hydrol. Process., 28, 3404-3418, https://doi.org/10.1002/hyp.9896, 2013.

Schaibly, J. H. and Shuler, K. E.: Study of the sensitivity of coupled reaction systems to uncertainties in rate coefficients. II Applications, J. Chem. Phys., 59, W07551, https://doi.org/10.1063/1.1680572, 1973.

Shamir, E., Imam, B., Gupta, H. V., and Sorooshian, S.: Application of temporal streamflow descriptors in hydrologic model parameter estimation, Water Resour. Res., 41, 1-16, https://doi.org/10.1029/2004WR003409, 2005a.

Shamir, E., Imam, B., Morin, E., Gupta, H. V., and Sorooshian, S.: The role of hydrograph indices in parameter estimation of rainfall-runoff models, Hydrol. Process., 19, 2187-2207, https://doi.org/10.1002/hyp.5676, 2005b.

Sieber, A. and Uhlenbrook, S.: Sensitivity analyses of a distributed catchment model to verify the model structure, J. Hydrol., 310, 216-235, https://doi.org/10.1016/j.jhydrol.2005.01.004, 2005.

Sivapalan, M.: Pattern, Process and Function: Elements of a Unified Theory of Hydrology at the Catchment Scale, in: Encyclopedia of Hydrological Sciences, APRIL 2006, John Wiley \& Sons, Ltd., 193-219, https://doi.org/10.1002/0470848944, 2005.

Song, X., Bryan, B. A., Almeida, A. C., Paul, K. I., Zhao, G., and Ren, Y.: Time-dependent sensitivity of a process-based ecological model, Ecol. Modell., 265, 114-123, https://doi.org/10.1016/j.ecolmodel.2013.06.013, 2013.

Sudheer, K. P., Lakshmi, G., and Chaubey, I.: Application of a pseudo simulator to evaluate the sensitivity of parameters in complex watershed models, Environ. Modell. Softw., 26, 135-143, https://doi.org/10.1016/j.envsoft.2010.07.007, 2011.

Tang, Y., Reed, P., Wagener, T., and van Werkhoven, K.: Comparing sensitivity analysis methods to advance lumped watershed model identification and evaluation, Hydrol. Earth Syst. Sci., 11, 793817, https://doi.org/10.5194/hess-11-793-2007, 2007.

Tolson, B. A. and Shoemaker, C. A.: Dynamically dimensioned search algorithm for computationally efficient watershed model calibration, Water Resour. Res., 43, 1-16, https://doi.org/10.1029/2005WR004723, 2007.

van Griensven, A., Meixner, T., Grunwald, S., Bishop, T., Diluzio, M., and Srinivasan, R.: A global sensitivity analysis tool for the 
parameters of multi-variable catchment models, J. Hydrol., 324, 10-23, https://doi.org/10.1016/j.jhydrol.2005.09.008, 2006.

van Werkhoven, K., Wagener, T., Reed, P., and Tang, Y.: Sensitivityguided reduction of parametric dimensionality for multiobjective calibration of watershed models, Adv. Water Res., 32, 1154-1169, https://doi.org/10.1016/j.advwatres.2009.03.002, 2009.

Vrugt, J. A. and Sadegh, M.: Toward diagnostic model calibration and evaluation: Approximate Bayesian computation, Water Resour. Res., 49, 4335-4345, https://doi.org/10.1002/wrcr.20354, 2013.

Wagener, T., Sivapalan, M., Troch, P., and Woods, R.: Catchment Classification and Hydrologic Similarity, Geography Compass, 1, 1-31, https://doi.org/10.1111/j.1749-8198.2007.00039.x, 2007.

Wagener, T., van Werkhoven, K., Reed, P., and Tang, Y.: Multiobjective sensitivity analysis to understand the information content in streamflow observations for distributed watershed modeling, Water Resour. Res., 45, 1-5, https://doi.org/10.1029/2008WR007347, 2009.
Winsemius, H. C., Schaefli, B., Montanari, A., and Savenije, H. H. G.: On the calibration of hydrological models in ungauged basins: A framework for integrating hard and soft hydrological information, Water Resour. Res., 45, W12422, https://doi.org/10.1029/2009WR007706, 2009.

Yadav, M., Wagener, T., and Gupta, H.: Regionalization of constraints on expected watershed response behavior for improved predictions in ungauged basins, Adv. Water Res., 30, 1756-1774, https://doi.org/10.1016/j.advwatres.2007.01.005, 2007.

Yilmaz, K. K., Gupta, H. V., and Wagener, T.: A process-based diagnostic approach to model evaluation: Application to the NWS distributed hydrologic model, Water Resour. Res., 44, 1-18, https://doi.org/10.1029/2007WR006716, 2008.

Zajac, Z. B.: Global sensitivity and uncertainty analysis of spatially distributed watershed models, $\mathrm{PhD}$ thesis, University of Florida, 195 pp., 2010. 